\title{
Identification of an anti-inflammatory protein from Faecalibacterium prausnitzii, a commensal bacterium deficient in Crohn's disease
}

\author{
E. Quévrain $\# 1,2,3$, M. A. Maubert ${ }^{\# 1,2,3,4}$, C. Michon ${ }^{\# 5,6}$, F. Chain ${ }^{5,6}$, R. Marquant ${ }^{1,3,10}$, J. \\ Tailhades $^{1,3,10}$, S. Miquel ${ }^{5,6}$, L. Carlier ${ }^{1,3,10}$, L. G. Bermúdez-Humarán ${ }^{5,6}$, B. Pigneur ${ }^{1,2,3}, \mathbf{O}$. \\ Lequin $^{1,3,10}$, P. Kharrat ${ }^{5,6}$, G. Thomas ${ }^{1,2,3}$, D. Rainteau ${ }^{1,2,3,4}$, C. Aubry ${ }^{5,6}$, N. Breyner ${ }^{5,6}$, C. \\ Afonso $^{7}$, S. Lavielle ${ }^{1,3,10}$, J.-P. Grill ${ }^{1,2,3}$, G. Chassaing ${ }^{1,3,10}$, J. M. Chatel ${ }^{5,6}$, G. Trugnan ${ }^{1,2,3,4}$, \\ R. Xavier ${ }^{8}$, P. Langella ${ }^{5,6}$, H. Sokol ${ }^{\# 1,2,3,5,9}$, and P. Seksik $\# 1,2,3,9$ \\ (1)Sorbonne Universités, UPMC Univ Paris 06, LBM, 27 rue de Chaligny, F-75012, Paris, France. \\ (2)INSERM-ERL 1157 and Inflammation-Immunopathology-Biotherapy Department (DHU i2B), \\ CHU Saint-Antoine 27 rue de Chaligny, F-75012 Paris, France.
}

(3)CNRS, UMR 7203 LBM, F-75005, Paris, France

(4)APHP, Hôpital Saint Antoine - Département PM2 Plateforme de Métabolomique, Peptidomique et dosage de Médicaments, F-75012 Paris, France

(5)INRA, UMR1319 Micalis, F-78350 Jouy-en-Josas, France.

(6)AgroParisTech, UMR Micalis, F-78350 Jouy-en-Josas, France.

(7)Université de Rouen, UMR 6014 COBRA / IRCOF, F-76130 Mont Saint Aignan, France

${ }^{(8)}$ Center for Systems Biology, Massachusetts General Hospital, Boston, Massachusetts, USA.

${ }^{(9)}$ APHP, Hôpital Saint Antoine - Service de Gastroentérologie et nutrition, F-75012 Paris, France

${ }^{(10)}$ Ecole Normale Supérieure- PSL Research University, Département de Chimie 24 rue Lhomond, F-75005 Paris, France

\# These authors contributed equally to this work.

\section{Abstract}

Background-Crohn's disease (CD) associated dysbiosis is characterized by a loss of Faecalibacterium prausnitzii, whose culture supernatant exerts an anti-inflammatory effect both in vitro and in vivo. However, the chemical nature of the anti-inflammatory compounds has not yet been determined.

\begin{abstract}
Methods-Peptidomic analysis using mass spectrometry was applied to F. prausnitzii supernatant. Anti-inflammatory effects of identified peptides were tested in vitro directly on
\end{abstract}

Corresponding author: Pr. Philippe SEKSIK, Service de Gastroentérologie et Nutrition, Hôpital St-Antoine, 184 rue du Faubourg StAntoine, 75571 Paris CEDEX 12, France. Tel: (+33) 149283162, Fax: (+33) 149283188, philippe.seksik@ sat.aphp.fr. Philippe Seksik declares consulting fees from Abbvie, MSD and Biocodex. Harry Sokol received consulting fee from Danone and Enterome and lecture fee from Abbvie and Biocodex. For the other authors, they declare that the research was conducted in the absence of any commercial or financial relationships that could be construed as a potential conflict of interest. 
intestinal epithelial cell lines and on cell lines transfected with a plasmid construction coding for the candidate protein encompassing these peptides. In vivo, the cDNA of the candidate protein was delivered to the gut by recombinant Lactic Acid Bacteria to prevent DNBS-colitis in mice.

Results-The seven peptides, identified in the F. prausnitzii culture supernatants, derived from a single Microbial Anti-inflammatory Molecule (MAM), a protein of $15 \mathrm{kDa}$ and comprising 53\% of nonpolar residues. This last feature prevented the direct characterization of the putative antiinflammatory activity of MAM-derived peptides. Transfection of MAM cDNA in epithelial cells led to a significant decrease in the activation of the NF- $\kappa$ B pathway with a dose-dependent effect. Finally, the use of a food-grade bacterium, Lactococcus lactis, delivering a plasmid encoding MAM was able to alleviate DNBS-induced colitis in mice.

Conclusion-A $15 \mathrm{kDa}$ protein with anti-inflammatory properties is produced by $F$. prausnitzii, a commensal bacterium involved in CD pathogenesis. This protein is able to inhibit the NF- $\mathrm{KB}$ pathway in intestinal epithelial cells and to prevent colitis in an animal model.

\section{Keywords}

microbiota; dysbiosis; Crohn's disease; Faecalibacterium prausnitzii; anti-inflammatory protein

\section{Background}

Evidence from immunological, microbiological and genetic studies implicates abnormal host-microbial interactions in the pathogenesis of Crohn's Disease (CD) [1] [2] [3] [4] [5]. Dysbiosis characterized by a reduction in bacterial biodiversity, lower bacterial population with anti-inflammatory properties and/or an increase in the proportion of bacteria with proinflammatory properties, has been observed in CD patients [6]. Several bacterial species have been associated with $\mathrm{CD}$, including members of the Proteobacteria [7] such as adherent-invasive Escherichia coli [8], Campylobacter concisus [9] [10] and enterohepatic Helicobacter [11] [12]. So far, no definitive proof for any specific etiological agent has been highlighted. Additionally, several $16 \mathrm{~S}$ rRNA sequencing-based studies have reported that members of the Firmicutes phylum were reduced in CD patients [13]. In previous work, we analyzed the composition of the ileal mucosa-associated microbiota of CD patients at the time of surgical resection for active disease, and six months later. Low proportions of Firmicutes, and particularly of Faecalibacterium prausnitzii, were consistently associated with an increased risk of post-operative recurrence of ileal CD [14]. Although controversial [15], we hypothesized that treatment with $F$. prausnitzii could be an effective strategy to counterbalance dysbiosis and reduce inflammation in CD patients. Following this, we and others demonstrated that $F$. prausnitzii exhibits anti-inflammatory effects both in vitro (cellular models) and in vivo (TNBS colitis model), associated with secreted metabolites that block NF- $\kappa B$ activation and IL-8 production by intestinal epithelial cells [14] [16] [17-18]. Moreover, gnotobiotic rodent models were previously used to show beneficial effects of $F$. prausnitzii on intestinal homeostasis and during an acute colitis [19] [20]. Identification of the active molecule(s) involved in this protective effect is of particular interest, since $F$. prausnitzii remains hardly cultivable due to its extreme oxygen sensitivity. Thus, finding the secreted molecule(s) responsible for this anti-inflammatory effect seems not only a cognitive issue but will also open the field of new therapeutic approach in CD. 
The cellular and molecular effects of commensal and probiotic bacteria are now recognized. Some bacteria have been shown to reinforce the intestinal barrier through the production of a soluble factor either by normalizing intestinal permeability of inflamed tissues [21] or inducing the expression of defensins [22] and type 2 zona occludens proteins in tight junctions between epithelial cells [23]. In mice, some commensal bacteria such as segmented filamentous bacteria [24] [25], Bacteroides fragilis and Clostridia members are able to shape gut immune responses [26] [27] [28] [29]. Among the molecules secreted by non-pathogenic bacteria, which are responsible for cellular effects in the host, very few bioactive molecules have been identified [30] [31]. An example of previously identified bioactive molecules can be seen in Lactobacillus rhamnosus GG, which secretes two proteins, p75 and p40, which have been characterized as being able to inhibit epithelial cells apoptosis induced by pro-inflammatory cytokines [32]. Small molecules, less than $10 \mathrm{kDa}$, from Saccharomyces boulardii and Bacteroides thetaiotaomicron that interact with NF- $\mathrm{kB}$ pathway have been detected but remain unidentified [33] [34]. Searching for such bioactive molecules remains challenging as finding these molecules in a cultured supernatant containing thousands of molecules is comparable to searching for a needle in a haystack. Preliminary experiments indicated that various treatments of $F$. prausnitzii supernatant (heated $>70^{\circ} \mathrm{c}$ ), enzyme digestion (trypsin, lipase, amylase) or filtration ( $\left.\mathrm{MW}<15 \mathrm{kDa}\right)$, do not suppress anti-inflammatory effects (Maubert M.A, unpublished data).

This prompted us to develop a peptidomic analysis of the supernatant in order to identify the presence of potential peptides derived from a unique and original protein from F. prausnitzii, which are able to interact with the NF- $\mathrm{kB}$ pathway in epithelial cells and are responsible for the anti-inflammatory effects.

\section{Methods}

\section{Faecalibacterium prausnitzii bacterial strain, culture conditions and supernatant preparation}

F. prausnitzii (strain A2-165) was grown overnight at $37^{\circ} \mathrm{C}$ in an anaerobic $\left(90 \% \mathrm{~N}_{2}, 5 \%\right.$ $\mathrm{CO}_{2}$ and $5 \% \mathrm{H}_{2}$ ) workstation (Whitley A35 anaerobic workstation) in LyBHI broth, $37 \mathrm{~g}$. $\mathrm{L}^{-1}$ of brain-heart infusion (Difco) and $5 \mathrm{~g}$. $\mathrm{L}^{-1}$ of yeast extract (Conda) at $\mathrm{pH}$ 7. The culture supernatant of $F$. prausnitzii was obtained by centrifugation at $1700 \mathrm{~g}$ at $4^{\circ} \mathrm{C}$ for 20 $\min$.

\section{Faecalibacterium prausnitzii supernatant analysis}

Fractionation of the F. prausnitzii culture medium -A solid/liquid extraction of culture medium using Waters Oasis HLB ${ }^{\circledR}$ SPE cartridges was carried out. Fractions were obtained by eluting with $20 \%, 40 \%$ and $80 \%$ of acetonitrile (F1, F2, F3 for F. prausnitzii supernatant and F1', F2', F3' for LyBHI culture medium). After freeze-drying, these fractions were tested on epithelial cells through a cellular assay for anti-inflammatory effect (see below). For further investigations in mass spectrometry, F2/F2' fractions were purified by preparative HPLC using a Waters Symmetry ${ }^{\circledR} \mathrm{C} 8$ column $(7.8 \times 300 \mathrm{~mm})$ 
Comparative mass spectrometry analysis of $\mathrm{F}$. prausnitzii culture medium-

The bioactive anti-inflammatory fractions from the culture supernatant and LyBHI fractions eluted by SPE were analyzed by MALDI-TOF mass spectrometry (Voyager ${ }^{\circledR}$ DE Pro -AB Sciex).

\section{Peptide identification and synthesis}

Identification of peptides by FT-ICR mass spectrometry-The ions of interest were fragmented by a FT-ICR mass spectrometer, equipped with a 7T superconducting magnet (Apex $\mathrm{Qe}^{\circledR}$, Bruker Daltonics). The peptides were then identified by complete de novo sequencing.

Peptides and functionalized peptides synthesis-All protected amino acids were commercially available from Iris Biotech GMBH or Bachem. Peptide syntheses were carried out on a 0.1-mmol scale using an ABI Model 431A peptide synthesizer (Applied BioSystems), starting from the appropriate Wang Tentagel resin, with 10 equiv. of the protected Fmoc-amino acid and HBTU/DIEA for the activation. The crude peptides were purified by HPLC to obtain purity over $97 \%$.

\section{Production of MAM protein in a bacterial heterologous system}

The gene encoding the MAM protein was PCR amplified from genomic DNA. PCR product was digested, purified, and cloned in PSTABY plasmid and introduced in Escherichia coli. Protein extraction was carried out and verified by Coomassie blue staining and Western Blot.

\section{Cellular assays for anti-inflammatory effect}

Intestinal epithelial cell lines (Caco-2, HT29 and mucus-secreting HT29-MTX), from the European Collection of Cell Cultures (Wiltshire, United Kingdom) and INSERM U505 (Institut des Cordeliers, France), were cultured in supplemented DMEM (PAA) at $37^{\circ} \mathrm{C}$ in a $5 \% \mathrm{CO}_{2}$ incubator. Cells were incubated with different $F$. prausnitzii supernatant fractions $(1 / 100,1 / 500$ and $1 / 1000$ dilutions in DMEM medium) or molecules of interest (2 to $10 \mu \mathrm{M})$ and, according to the cell lines used, stimulated with various pro-inflammatory cytokines (IL-1 $\beta 15 \mathrm{ng}$. $\mathrm{mL}^{-1}$ or TNFa $10 \mathrm{ng}$. $\mathrm{mL}^{-1}$ ). After $6 \mathrm{~h}$ incubation, cell supernatants were removed for IL-8 analysis. Protein concentrations were determined in cell lysates using Bicinchoninic acid protein assay (Pierce, Rockford, IL) according to the manufacturers instructions. The IL-8 level was determined in duplicate in cell supernatants using ELISA kit DuoSet (R\&D systems, Minneapolis, MN). Effect on NF- $\kappa B$ pathway (phosphorylated and total JNK, P38, ERK1/2, IкB, NF- $\mathrm{kB}$ ) of $F$. prausnitzii supernatant was tested on Caco-2 cell line using multiplex assay (Bio-Plex ${ }^{\circledR}$ Bio-Rad).

Transfected cell lines and NFKB reporter assay-The cDNA encoding the protein ZP05614546.1 was cloned in 3xFlag (C-term) pCMV vector. Transfection was performed using transfectin ${ }^{\mathrm{TM}}$ Lipid reagent (Bio-Rad) in opti-MEM ${ }^{\circledR}$ medium (Gibco, Life Technologies) in different epithelial cells, namely HEK293T, HT29, and TLR4/MD2/CD14 stably-transfected HEK293T (Invivogen). Different concentrations of cDNA, depending on the considered plasmid, were used: $0.8 \mathrm{ng} . \mu \mathrm{L}^{-1}$ of the plasmid MAM, the plasmid containing cDNA of Carma1 and their empty equivalents, $0.08 \mathrm{ng} . \mu \mathrm{L}^{-1}$ of the NF- $\mathrm{kB}$ 
reporter plasmid and $0.2 \mathrm{pg} . \mu \mathrm{L}^{-1}$ of the Renilla luciferase control reporter vector. For HEK293T-TLR4/MD2/CD14, activation of the NF- $\kappa B$ pathway was performed by administration of LPS $100 \mathrm{ng} . \mathrm{mL}^{-1}$ (Sigma-Aldrich). Positive control of inhibition of NF-

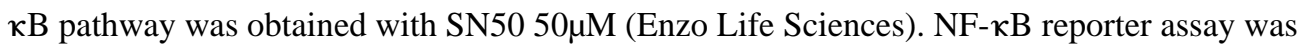
carried out, after 24h incubation, using Dual-Luciferase ${ }^{\circledR}$ Reporter Assay system (Promega). In the same manner, MAM activity on STAT3 pathway, activated by colivelin $0.1 \mathrm{nM}$ (Santa Cruz Biotechnology), was evaluated.

\section{Cellular imaging IF in Hela transfected cells}

HeLa or HEK293T (both from American Type Culture Collection) cells were grown in DMEM (Invitrogen) with $10 \% \mathrm{FCS}$ (HyClone) at $37^{\circ} \mathrm{C}$ and $5 \% \mathrm{CO}$.

Twenty-four hours following transfection, cells were washed and fixed. Cells were stained using appropriate antibodies for $1 \mathrm{~h}$. Cells were imaged using a Leica SP5 confocal microscope.

\section{In vivo assays for anti-inflammatory effect of MAM protein}

Plasmid construction-MAM encoding plasmid (pILMAM) was created by a fusion between pIL253 [35] cut with Pst (Fermentas) and pCMV including DNA of MAM (see above) cut with $S b f l$. Empty equivalent (pILEMPTY) was created using the same method, but with fusion of pIL253 empty pCMV. pILMAM and pILEMPTY were transformed in $L$. lactis MG1363 as described by Langella et al. (1993) [36]. L. lactis strains were thereafter grown on M17 medium.

DNBS-Induced Colitis-Mice were fed with L. lactis harboring pILMAM or pILEMPTY plasmid. After acclimatization, bacterial suspensions of L. lactis MG1363 $\left(5.10^{9} \mathrm{CFU}\right.$ in $200 \mu \mathrm{L}$ ), were administered to mice (C57BL/6, 6 weeks, male) daily by intragastric gavage from day 7 before until day 3 after induction of colitis. DNBS solution in $30 \%$ ethanol was administered intrarectally (at a dose of $100 \mathrm{mg}$. $\mathrm{kg}^{-1}$ body weight). Inflammation was monitored $72 \mathrm{~h}$ after DNBS administration. Mice were weighed before DNBS administration and at killing. Two groups of 8 mice were investigated, fed with L. lactis harboring pILMAM or pILEMPTY. Experiments were performed 3 times.

Inflammation Score Assessment of DNBS Colitis-The colon was removed, dissected free of fat and mesentery, carefully opened, and cleaned. Colon length was measured. Colonic damage and inflammation were assessed blindly according to the Wallace criteria. For histological assessment, a colon sample located in the most inflamed area was fixed in $4 \%$ paraformaldehyde acid (Sigma) and embedded in paraffin. Four micrometer sections were stained with hematoxylin/eosin and examined blindly according to the method described by Dieleman et al [37]. Histological scores were carried out according to Ameho criteria.

MAM detection from mice purified intestinal epithelial cells-Small and large intestine were dissected, washed, cut in $1 \mathrm{~cm}$ pieces and incubated for $20 \mathrm{~min}$ at $37^{\circ} \mathrm{C}, 250$ rpm in extraction buffer (EDTA $5 \mathrm{mM}$, DTT $0.145 \mathrm{mg}$. $\mathrm{mL}^{-1}, 25 \mathrm{mM}$ HEPES, $50 \mu \mathrm{M} 2$ - 
mercaptoethanol (Sigma), RPMI (Lonza)). After incubation remaining solid tissues were withdrawn. Incubation mix containing epithelial cells was centrifuged and pellets lyzed by ultrasound in cold PBS (Lonza). After centrifugation supernatant was kept at $-80^{\circ} \mathrm{C}$ in RNAlater (Qiagen) and RNA was extracted with RNeasy Mini Kit (Qiagen). Retro Transcription was performed using SuperScript ${ }^{\circledR}$ II Reverse Transcriptase (Sigma) with random primers. RT-PCR for MAM mRNA detection was performed using Phusion HighFidelity DNA Polymerase (Thermo Scientific) with the following primers: $5^{\prime}$ ACTCTGGTTGGCAACACCTT- $3{ }^{\prime}$ and $5^{\prime}$-CGATCGGGTTGCCCTTAACA- 3 '. Immunoblotting targeting the FLAG region of the MAM expressed protein (pILMAM construct) was used to detect MAM in purified epithelial cells from gut mucosa of sacrificed mice (on day 3 ).

Lymphocyte Isolation and Measurement of Cytokine Production-Lymphocyte suspensions were prepared from the Mesenteric Lymph Nodes (MLN) by pressing cells through a 70-mmol/L Falcon nylon cell strainer (BD Biosciences, San Jose, CA).

Lymphocytes were counted by flow cytometry (Accuri C6), resuspended in culture medium (RPMI, Lonza with 100 Unit of Streptomicin Penicilin, PAA Laboratories and 10\% SVF, Lonza) and activated with coated anti-mouse antibody CD3e and CD28 (eBioscience). Cytokine production was assessed in supernatant by ELISA (IL-17A and INF- $\gamma$, Mabtech) after $48 \mathrm{~h}$ incubation.

MAM detection from dixenic mice-Caecum content of gnotobiotic mice harboring $F$. prausnitzii (A2-165) and Escherichia coli (K-12 JM105) subjected to 2,4,6-

trinitrobenzenesulfonic acid (TNBS)-induced acute colitis were gifted by Sylvie Miquel and Muriel Thomas. To obtain dixenic E. coli/F. prausnitzii-diassociated mice, BALB/c germfree mice (obtained from the germfree rodent breeding facilities of Anaxem-Micalis; INRA, Jouy-en-Josas, France) were orally inoculated with a fresh culture of E. coli JM105 (10 8 to $10^{9} \mathrm{CFU} / \mathrm{ml}$ ). Following this, the E. coli monoassociated mice were inoculated with $F$. prausnitzii A2-165 as previously described [19]. One month after the stable implantation of the two strains, mice were intrarectally inoculated with 2,4,6-trinitrobenzenesulfonic acid (TNBS) $(50 \mathrm{mg} / \mathrm{kg}$ body weight) to induce acute colitis, or with the vehicule $(0.9 \% \mathrm{NaCl}-$ ethanol) to obtain control mice [20]. Inflammation was monitored 48h after TNBS administration. $250 \mu \mathrm{L}$ of phenol $\mathrm{pH} 4,8$ / chloroforme-isoamylalcohol (5:1) (Sigma) was added to caecum contents and the mix was agitated strongly. After shaking, $12.5 \mu \mathrm{L}$ of SDS $20 \%$ and $25 \mu \mathrm{L}$ of sodium acetate at $3 \mathrm{M} \mathrm{pH} 8$ was added. Samples were mixed with fast prep $40 \mathrm{~s}$ at power 5 and $20 \mathrm{~s}$ at power 5 , followed by centrifugation for $15 \mathrm{~min}$ at $13000 \mathrm{~g}$. Superior phases were mixed with $250 \mu \mathrm{L}$ of chloroforme-isoamylalcohol and centrifuged. Superior phases were treated with High Pure RNA Isolation Kit (Roche) according the manufacturers instructions. Retro Transcription was performed using SuperScript ${ }^{\circledR}$ II Reverse Transcriptase (Sigma) with the following primers: $5^{\prime}$ ACTCTGGTTGGCAACACCTT- $3^{\prime}$ and $5^{\prime}$-CGATCGGGTTGCCCTTAACA-3 ${ }^{\prime}$. RT-PCR for MAM mRNA detection was performed using Phusion High-Fidelity DNA Polymerase (Thermo Scientific) with the following primers: $5^{\prime}$-ACTCTGGTTGGCAACACCTT- ${ }^{\prime}$ and 5'-CGATCGGGTTGCCCTTAACA-3' . 


\section{Statistical analysis}

Statistical analysis for significant differences was performed using Student's t-test or MannWhitney test when appropriate using JMP ${ }^{\circledR}$ software (Abacus Concepts, Berkeley, CA). Animal experiments were performed three times. Statistical significance was considered when $P<0.05$.

\section{Results}

\section{Identification of MAM protein}

Peptidomic analysis of F. prausnitzii supernatant-Two fractions (F2 and F3) from F. prausnitzii supernatant exerted inhibitory effects on IL1- $\beta$-induced IL-8 secretion in intestinal epithelial Caco2 cells (Figure 1). For comparison, the MALDI-TOF MS spectra generated from the culture medium fractions F2' and F3' and F. prausnitzii culture supernatant fractions F2 and F3 were also analysed.

Analysis of F2' and F3' vs F2 and F3 using MALDI-TOF MS allowed us to detect seven ions $\left([\mathrm{M}+\mathrm{H}]^{+} \mathrm{m} / \mathrm{z} 1733.93,1832.92,1946.97,2047.95,2146.94,2579.72\right.$ and 4601.06) in F2 and F3 fractions only (Figure 2 A-B and Supplementary files S1, S2, S3). The seven ions of interest were fragmented by an ESI FT-ICR mass spectrometer, and identified by de novo sequencing.

To illustrate the identification of compounds, one ion of interest (here: $\mathrm{m} / \mathrm{z} 2146.94$ ) corresponding to $[\mathrm{M}+2 \mathrm{H}]^{2+} \mathrm{m} / \mathrm{z} 1073.61$ was fragmented by collision induced dissociation (CID) (Figure $2 \mathrm{C}$ ). From various CID spectra (zoom, deconvoluted, product ion at [M $+2 \mathrm{H}]^{2+} \mathrm{m} / \mathrm{z}$ 831.96), the complete sequence was finally obtained unambiguously: VT[I/ L]VGNTF[I/L]QST[I/L]NRT[I/L]GV[I/L] (supplementary files S4, S5 and S6). The isomeric amino acids in square brackets [I or L] were undefined. The same procedure was used to determine the sequence of the 6 other peptides.

Identification of a protein and its derived peptides from F. prausnitzii-The in silico analysis of $F$. prausnitzii genome (Blast and ProteinInfo software with NCBInr) first allowed to complete the sequence of the peptide $4600.28 \mathrm{Da}$, removing any ambiguity between leucine and isoleucine, and then to demonstrate that the seven isolated peptides all derived from the F. prausnitzii protein ZP 05614546.1.

Sequences of protein ZP 05614546.1, called MAM (Microbial Anti-inflammatory Molecule or named after its discoverer Marie-Anne Maubert), and its derived peptides are presented in table 1 .

To investigate structure/function relationships of MAM protein, a sequence search was performed using the program BLAST. The BLAST search recovered several sequences that are homologous to MAM, all belonging to F. prausnitzii strains (Figure 3), with statistically significant, low e-values. The sequence alignment of MAM to its other $F$. prausnitzii counterparts (Figure 3 ) revealed high sequence identity (> 34\%), with strong sequence conservation in the 1-71 N-terminal part and in the 105-118 segment (MAM numbering). 
The characterized peptides Pep1-5 corresponded to a region of the protein, which is conserved in F. prausnitzii orthologs.

A sequence analysis based on ExPASy bioinformatics tools indicated that MAM does not contain regions of low sequence complexity and intrinsic disorder, and should therefore adopt a compact, globular fold. Although the sequence exhibited two highly hydrophobic regions around residues 23-38 and 103-121, MAM was not predicted as a transmembrane protein using DAS-TM, HMMTOP or PHDhtm programs.

In order to get further structural information on MAM protein, the results of the BLAST search were examined using the hits displaying higher e-values. Some sequence similarity was observed with proteins belonging to other Firmicutes (Roseburia intestinalis) having a putative GGDEF domain. A sequence alignment of MAM with this GGDEF domain yielded $15 \%$ sequence identity and 38\% sequence similarity over the whole sequence, both proteins having comparable sizes (Figure 4A). Based on these results, a homology model was tentatively built using Modeller program [38] (Figure 4C). The inspection of the model indicated that the spatial distribution of polar and hydrophobic residues was compatible with such a globular fold. GGDEF domains share a $\alpha / \beta$ topology typically composed of a fivestranded $\beta$-sheet core flanked by five $\alpha$-helices (Figure 4B). The alignment showed that the short $C$-terminal $\beta$-strand was absent in the MAM model, as also observed in some GGDEF domains [39]. Interestingly, the region encompassing the characterized peptides Pep1-5 corresponds to helix $\mathrm{H} 3$ and is exposed at the surface of the model (Figure 4C).

\section{Anti-inflammatory effect of the MAM protein}

\section{Direct anti-inflammatory effect of MAM protein and its derived peptides-}

MAM protein produced through heterologous expression system (e.g. E. coli) was systematically found in hydrophobic fractions, thus compromising any direct testing of antiinflammatory effects. To circumvent this problem, MAM derived peptides were functionalized (pegylation, CPP coupling, modification of peptidic bond...), and/or mixed with amphiphilic partners to optimize their solubility. However, none of these compounds showed significant and reproducible anti-inflammatory effect in cellular assays. We thus decided to change our strategy. Previous experiments suggested that $F$. prausnitzii supernatant acts distally on NF- $\kappa \mathrm{B}$ pathway in epithelial cells (data not shown). We reasoned that MAM or its derived peptides could act on intracellular targets. We thus assessed the effect of direct overexpression of MAM protein in epithelial cells.

\section{Anti-inflammatory effect of MAM protein after transfection in eukaryotic} epithelial cells-A full-length Flag-MAM cDNA was transfected in HEK293T and HT29 cells and the effect of the expressed protein was tested on NF- $\kappa$ B pathway, since preliminary experiments, using a multiplex assay (see Material and Methods), suggested an effect on the distal part of this pathway (data not shown).

Expression of MAM was confirmed in HEK293T, MD2-TLR4-CD14 HEK293T and HT29 cells by Western blot analysis with anti-Flag antibody (supplementary file S7). Using a NF$\kappa \mathrm{B}$ reporter system in these human epithelial cells, we showed that expression of MAM protein was able to block NF- $\mathrm{BB}$ activation induced by Carma-1 or LPS in a dose-dependent 
manner (Figure $5 \mathrm{~A}-\mathrm{C}$ ). The specificity of the NF- $\mathrm{\kappa B}$ activation in our system was validated by the inhibitor effect of SN50, a well known NF- $\mathrm{kB}$ inhibitor. Moreover, the specificity of the effect of MAM on the NF- $\mathrm{B}$ pathway was highlighted by the lack of effect on STAT3 pathway in the same eukaryotic system (Figure 5 D).

When NF- $\kappa B$ activation was performed using I $\kappa$ B (distal part of the NF- $\kappa B$ pathway), MAM transfected cells still exhibited a reduced NF- $\kappa B$ activity (Figure 6).

\section{Subcellular location of MAM protein in HeLa and in HEK293T cells-In} agreement with this last result, MAM protein was localized around the cell nucleus in MAM-Flag transfected HeLa cells (Figure 7 A-D) and co-localized with I $\kappa$ B in transfected HEK293T (Figure 7 E-H).

MAM effect in DNBS-induced colitis in mice-To mimic more adequately the in vivo situation, a food-grade bacterium, Lactoccocus lactis was modified to produce the cDNA coding for MAM, resulting in a kind of "in vivo transfection". This allowed delivery of MAM cDNA directly by bacteria in mice subjected to DNBS treatment. Although no heterologous protein is produced by the bacterial strain, we verified that there is no difference in the growth between L. lactis pILEMPTY and pILMAM (supplementary file S8). To confirm that our strategy effectively leads to in vivo production of MAM, we performed western blot analysis on small bowel and colon epithelial cells of mice fed with L. lactis (Figure 8). Expression of MAM at the mRNA level was also confirmed (supplementary file S9). Weight loss was significantly lesser in mice fed with L. lactis pILMAM at day 1 and 2 (Figure 9B). After dissection of the gut, the Wallace score was also significantly lower in pILMAM (Figure 9A). We subsequently isolated lymphocytes from MLN of both mice groups and assessed their cytokine production following stimulation with anti-CD3 and anti-CD28 antibodies. The two pro-inflammatory cytokines IL-17A and INF$\gamma$ were produced in lower amounts in cells isolated from $L$. lactis pILMAM fed mice (Figure 9C-D). No histological differences were observed between mice fed with $L$. lactis pILMAM and L. lactis pILEMPTY (supplementary file S10). Taken together, these results show that L. lactis pILMAM exhibits significant protective effect in DNBS-induced colitis.

MAM detection from dixenic mice: MAM mRNA was detected in vivo for the first time in our model of dixenic mice E. coli / F. prausnitzii (Figure 10). Sequencing confirmed that the detected mRNA was MAM encoding mRNA.

\section{Discussion}

Herein, we were able to identify a unique and original $15 \mathrm{kDa}$ protein (ZP05614546.1), called MAM, with anti-inflammatory properties produced by $F$. prausnitzii. This protein and/or derived peptides involved in the anti-inflammatory effect are able to inhibit the NF$\mathrm{B}$ pathway in several intestinal epithelial cells lines. Interestingly, L. lactis delivering a MAM encoding plasmid was also able to prevent DNBS-colitis in mice.

This discovery is in line with a series of work performed by our group. Indeed, for many years, we and others have described CD-associated dysbiosis and observed a strong 
restriction in the biodiversity of the Firmicutes (one of the two major bacterial phyla in the normal gut microbiota [40]) and a quantitative decrease in bacteria belonging to Clostridium leptum group [6] [14] [41]. Faecalibacterium prausnitzii is a dominant species of this group. We have gone a step further, looking at the impact of these changes in gut microbiome on CD patient outcomes and inflammation pathways. In this setting, we were able to show that low level of $F$. prausnitzii in ileal mucosa of CD patients was predictive of postoperative recurrence [14] and again, more recently, we observed that low level in F. prausnitzii in faeces was predictive of $\mathrm{CD}$ relapse in patients in remission [42]. Moreover, this bacterium exerts anti-inflammatory properties in vitro and in vivo [14]. In this previous work the antiinflammatory effects of $F$. prausnitzii were mediated by secreted molecules in the culture supernatant. These bioactive molecules were highly suspected to be protein-derived peptides from $F$. prausnitzii. Thus, it remained a major task to isolate these molecules, to characterize and to analyze their immunomodulatory effects.

We met several difficulties in achieving these goals. First, finding bioactive molecules in $F$. prausnitzii supernatant was challenging. We made it possible by using a bio-guided strategy generated from the culture medium fractions and differential MALDI-TOF MS analysis. Thanks to ultra-high resolution of the FT-ICR, the complete sequences of the peptides were finally obtained unambiguously by de novo sequencing. To note, the easy coupling of mass spectrometry with separation techniques, such as liquid chromatography, and its sensitivity makes it a method of choice for detection of various molecules present at trace levels in complex mixtures, such as a bacterial supernatant. Surprisingly, after in silico analysis, the seven peptides all originate from the same unknown protein ZP05614546.1 from $F$. prausnitzii. Some sequence similarities were observed with proteins belonging to other Firmicutes (Roseburia intestinalis) having a putative GGDEF domain. These proteins are described in the UnitProtKB database as putative since they have not yet been characterized and have unknown functions. Strikingly, MAM protein does not resemble any other known protein from Gram-positive or Gram-negative bacteria. These GGDEF domains are typically found in enzymes endowed with diguanylate cyclase activity and involved in the biosynthesis of cyclic di-GMP, a widespread signaling molecule in bacteria [43]. Accordingly, a BLAST search against the PDB database also revealed a hit with a protein from Methylococcus capsulatus containing a GGDEF domain. Although MAM protein might fold as a GGDEF domain, it lacks the critical catalytic residues (including the GGDEF sequence) that are involved in diguanylate cyclase activity. Furthermore, other residues involved in nucleotide binding such as the RXXD motif [39] are also missing. It is therefore very unlikely that MAM has any catalytic or regulatory functions involved in cyclic di-GMP signaling. Thus, no clear function could be assigned to this protein.

High prevalence of nonpolar residues prevented us to provide direct characterization of the putative anti-inflammatory activity. To overcome this technical lock, we applied a molecular approach by transfecting MAM cDNA in a series of epithelial cell lines and showing a significant decrease in the activation of the NF- $\kappa B$ pathway with a dose-dependent effect. Finally, a $L$. lactis strain delivering a MAM encoding plasmid was able to prevent DNBS colitis in mice. These results demonstrate that MAM protein supports, at least partly, the anti-inflammatory effect exerted by $F$. prausnitzii. 
One can hypothesized that $F$. prausnitzii could exert its anti-inflammatory effect on host cells through many molecular patterns. In fact, when performing preliminary experiments on $F$. prausnitzii supernatant, we observed that anti-inflammatory effect was not abrogated by heat (above $70^{\circ} \mathrm{c}$ ), enzyme digestion (trypsin, lipase, amylase) or MW filtration (below $15 \mathrm{kDa}$ ) (Maubert M. A., unpublished data). This indicates that various metabolites other than MAM could contribute to this effect. Furthermore, it has been shown recently that $F$. prausnitzii is a major inducer of Clostridium-specific IL-10-secreting regulatory T cell subset present in the human colonic lamina propria and blood [44]. This indicates that several cell types are targeted through interactions between F. prausnitzii and the host to maintain and shape gut barrier immune function. In this setting, bacterial metabolites such as the abundant microbial-derived short-chain fatty acids (SCFA) have been identified to induce signaling effects regulating colonic regulatory $\mathrm{T}$ cell homeostasis [30]. To note human colonic butyrate producers are Gram-positive Firmicutes from which the two most abundant groups are related to Roseburia spp. and to F. prausnitzii. In fact, the intestinal tract of mammals is home to $10^{13}$ to $10^{14}$ commensal bacteria composed of hundreds of species of which certain are able to play specific roles in determining the immunological balance in host [27 45]. Atarashi and colleagues have recently demonstrated that Clostridial species induce regulatory T cells through SCFA pathway stimulating epithelial cells to produce TGF $\beta$, contributing to regulatory $\mathrm{T}$ cells differentiation and expansion [46]. Other species-specific bacterial molecules, such as $B$. fragilis-derived polysaccharide A, have previously been demonstrated to have immunomodulatory functions [47] [48] [49]. Another study demonstrated that a mixture of probiotic strains, including Lactobacillus and Bifidobacterium, enhanced the production of TGF- $\beta$ and IDO from dendritic cells and consequently induced Treg cells [50]. Thus, our work uncovering a new anti-inflammatory protein from $F$. prausnitzii, a major microbiota species of gut microbiota, reinforces the role of a metabolic interface of promiscuous bacterial molecules on gut mucosa physiology.

However, a metabolomic approach based on gnotobiotic model permitted to propose other hypothesis concerning F. prausnitzii anti-inflammatory properties [20]. Authors identified various metabolites, particularly salicylic acid, specifically associated with the presence of $F$. prausnitzii. This study, associated to our results, confirm the complex action mechanisms of F. prausnitzii to limit the inflammatory process.

To conclude, our work opens new lines of evidence that the impact of CD-associated dysbiosis could, at term, change our practice and lead to novel strategies to prevent and treat inflammatory bowel diseases. Although discovering an anti-inflammatory molecule constitutes a first step towards new anti-inflammatory drugs in CD, MAM could represent a targeted biomarker for $\mathrm{CD}$, regarding the value of $F$. prausnitzii for predicting $\mathrm{CD}$ relapse. In these perspectives, there is further need for deciphering the role of MAM in the gut ecosystem. In particular, emphasis should be placed on finding the function of MAM and the mechanism of its production within the bacteria before considering it a target for $\mathrm{CD}$ management.

\section{Supplementary Material}

Refer to Web version on PubMed Central for supplementary material. 


\title{
Acknowledgments
}

We thank Association François Aupetit (2009) and Agence Nationale de la Recherche (Mi2 2010) for funding this work. We also thank Lucette Groisard, Loïc Brot, Chantal Bridonneau and Isabelle Naas for technical assistance and Joëlle Masliah and Muriel Thomas for their scientific support. Marie-Anne Maubert thanks Jean Claude Tabet and the TGE High Field FT-ICR (CNRS) for providing the access to the FT-ICR mass spectrometer. Caecum content of Gnotobiotic mice harboring F. prausnitzii (A2-165) and Escherichia coli (K-12 JM105) subjected to 2,4,6-trinitrobenzenesulfonic acid (TNBS)-induced acute colitis have been gently given by Sylvie Miquel and Muriel Thomas. This last study was a part of the FPARIS collaborative project selected and supported by the Vitagora Competitive Cluster and funded by the French FUI (Fond Unique Interministériel; FUI no. F1010012D), the FEDER (Fonds Européen de Développement Régional; Bourgogne no. 34606), the Burgundy Region, the Conseil Général 21, and the Grand Dijon. This work was also supported by Merck Médication Familiale (Dijon, France) and Biovitis (Saint Étienne de Chomeil, France).

\section{Abbreviations}

\author{
IBD inflammatory bowel disease \\ CD Crohn's disease \\ MALDI-TOFMatrix-Assisted Laser Desorption/Ionisation - Time Of Flight \\ FT-ICR Fourier Transform - Ion Cyclotron Resonance \\ HPLC High-performance liquid chromatography \\ DNBS Dinitrobenzene Sulfonic Acid \\ TNBS Trinitrobenzene Sulfonic acid
}

\section{References}

1. MacDermott RP. Alterations of the mucosal immune system in inflammatory bowel disease. $\mathrm{J}$ Gastroenterol. 1996; 31:907-16. [PubMed: 9027661]

2. Hugot JP, Chamaillard M, Zouali H, et al. Association of NOD2 leucine-rich repeat variants with susceptibility to Crohn's disease. Nature. 2001; 411:599-603. [PubMed: 11385576]

3. Allez M, Mayer L. Regulatory T cells: peace keepers in the gut. Inflamm Bowel Dis. 2004; 10:66676. [PubMed: 15472533]

4. Sartor RB. Therapeutic manipulation of the enteric microflora in inflammatory bowel diseases: antibiotics, probiotics, and prebiotics. Gastroenterology. 2004; 126:1620-33. [PubMed: 15168372]

5. Khor B, Gardet A, Xavier RJ. Genetics and pathogenesis of inflammatory bowel disease. Nature. 2011; 474:307-17. [PubMed: 21677747]

6. Sokol H, Seksik P, Rigottier-Gois L, et al. Specificities of the fecal microbiota in inflammatory bowel disease. Inflamm Bowel Dis. 2006; 12:106-11. [PubMed: 16432374]

7. Mukhopadhya I, Hansen R, El-Omar EM, et al. IBD-what role do Proteobacteria play? Nat Rev Gastroenterol Hepatol. 2012; 9:219-30. [PubMed: 22349170]

8. Darfeuille-Michaud A, Boudeau J, Bulois P, et al. High prevalence of adherent-invasive Escherichia coli associated with ileal mucosa in Crohn's disease. Gastroenterology. 2004; 127:412-21. [PubMed: 15300573]

9. Man SM, Zhang L, Day AS, et al. Campylobacter concisus and other Campylobacter species in children with newly diagnosed Crohn's disease. Inflamm Bowel Dis. 2010; 16:1008-16. [PubMed: 19885905]

10. Kaakoush NO, Mitchell HM. Campylobacter concisus - A new player in intestinal disease. Front Cell Infect Microbiol. 2012; 2:4. [PubMed: 22919596] 
11. Bohr UR, Glasbrenner B, Primus A, et al. Identification of enterohepatic Helicobacter species in patients suffering from inflammatory bowel disease. J Clin Microbiol. 2004; 42:2766-8. [PubMed: 15184464]

12. Man SM, Zhang L, Day AS, et al. Detection of enterohepatic and gastric helicobacter species in fecal specimens of children with Crohn's disease. Helicobacter. 2008; 13:234-8. [PubMed: 18665930]

13. Sokol H, Seksik P, Furet JP, et al. Low counts of Faecalibacterium prausnitzii in colitis microbiota. Inflamm Bowel Dis. 2009; 15:1183-9. [PubMed: 19235886]

14. Sokol H, Pigneur B, Watterlot L, et al. Faecalibacterium prausnitzii is an anti-inflammatory commensal bacterium identified by gut microbiota analysis of Crohn disease patients. Proc Natl Acad Sci U S A. 2008; 105:16731-6. [PubMed: 18936492]

15. Hansen R, Russell RK, Reiff C, et al. Microbiota of de-novo pediatric IBD: increased Faecalibacterium prausnitzii and reduced bacterial diversity in Crohn's but not in ulcerative colitis. Am J Gastroenterol. 2012; 107:1913-22. [PubMed: 23044767]

16. Zhang M, Qiu X, Zhang H, et al. Faecalibacterium prausnitzii inhibits interleukin-17 to ameliorate colorectal colitis in rats. PLoS One. 2014; 9:e109146. [PubMed: 25275569]

17. Miquel S, Martin R, Rossi O, et al. Faecalibacterium prausnitzii and human intestinal health. Curr Opin Microbiol. 2013; 16:255-61. [PubMed: 23831042]

18. Martin R, Chain F, Miquel S, et al. The commensal bacterium Faecalibacterium prausnitzii is protective in DNBS-induced chronic moderate and severe colitis models. Inflamm Bowel Dis. 2014; 20:417-30. [PubMed: 24418903]

19. Wrzosek L, Miquel S, Noordine ML, et al. Bacteroides thetaiotaomicron and Faecalibacterium prausnitzii influence the production of mucus glycans and the development of goblet cells in the colonic epithelium of a gnotobiotic model rodent. BMC Biol. 2013; 11:61. [PubMed: 23692866]

20. Miquel S, Leclerc M, Martin R, et al. Identification of Metabolic Signatures Linked to AntiInflammatory Effects of Faecalibacterium prausnitzii. MBio. 2015; 6

21. Mennigen R, Nolte K, Rijcken E, et al. Probiotic mixture VSL\#3 protects the epithelial barrier by maintaining tight junction protein expression and preventing apoptosis in a murine model of colitis. Am J Physiol-Gastr L. 2009; 296:G1140-G49.

22. Vora P, Youdim A, Thomas LS, et al. beta-Defensin-2 expression is regulated by TLR signaling in intestinal epithelial cells. Journal of Immunology. 2004; 173:5398-405.

23. Zyrek AA, Cichon C, Helms S, et al. Molecular mechanisms underlying the probiotic effects of Escherichia coli Nissle 1917 involve ZO-2 and PKCzeta redistribution resulting in tight junction and epithelial barrier repair. Cell Microbiol. 2007; 9:804-16. [PubMed: 17087734]

24. Lecuyer E, Rakotobe S, Lengline-Garnier H, et al. Segmented filamentous bacterium uses secondary and tertiary lymphoid tissues to induce gut $\operatorname{IgA}$ and specific T helper 17 cell responses. Immunity. 2014; 40:608-20. [PubMed: 24745335]

25. Gaboriau-Routhiau V, Rakotobe S, Lecuyer E, et al. The key role of segmented filamentous bacteria in the coordinated maturation of gut helper T cell responses. Immunity. 2009; 31:677-89. [PubMed: 19833089]

26. Ivanov II, Atarashi K, Manel N, et al. Induction of intestinal Th17 cells by segmented filamentous bacteria. Cell. 2009; 139:485-98. [PubMed: 19836068]

27. Atarashi K, Tanoue T, Shima T, et al. Induction of colonic regulatory T cells by indigenous Clostridium species. Science. 2011; 331:337-41. [PubMed: 21205640]

28. Round JL, Mazmanian SK. The gut microbiota shapes intestinal immune responses during health and disease. Nat Rev Immunol. 2009; 9:313-23. [PubMed: 19343057]

29. Schnupf P, Gaboriau-Routhiau V, Cerf-Bensussan N. Host interactions with Segmented Filamentous Bacteria: an unusual trade-off that drives the post-natal maturation of the gut immune system. Semin Immunol. 2013; 25:342-51. [PubMed: 24184014]

30. Smith PM, Howitt MR, Panikov N, et al. The microbial metabolites, short-chain fatty acids, regulate colonic Treg cell homeostasis. Science. 2013; 341:569-73. [PubMed: 23828891]

31. Bouskra D, Brezillon C, Berard M, et al. Lymphoid tissue genesis induced by commensals through NOD1 regulates intestinal homeostasis. Nature. 2008; 456:507-10. [PubMed: 18987631] 
32. Yan F, Cao H, Cover TL, et al. Soluble proteins produced by probiotic bacteria regulate intestinal epithelial cell survival and growth. Gastroenterology. 2007; 132:562-75. [PubMed: 17258729]

33. Sougioultzis S, Simeonidis S, Bhaskar KR, et al. Saccharomyces boulardii produces a soluble antiinflammatory factor that inhibits NF-kappaB-mediated IL-8 gene expression. Biochem Biophys Res Commun. 2006; 343:69-76. [PubMed: 16529714]

34. Kelly D, Campbell JI, King TP, et al. Commensal anaerobic gut bacteria attenuate inflammation by regulating nuclear-cytoplasmic shuttling of PPAR-gamma and RelA. Nat Immunol. 2004; 5:10412. [PubMed: 14691478]

35. Holo H, Nes IF. High-Frequency Transformation, by Electroporation, of Lactococcus lactis subsp. cremoris Grown with Glycine in Osmotically Stabilized Media. Appl Environ Microbiol. 1989; 55:3119-23. [PubMed: 16348073]

36. Langella P, Le Loir Y, Ehrlich SD, et al. Efficient plasmid mobilization by pIP501 in Lactococcus lactis subsp. lactis. J Bacteriol. 1993; 175:5806-13. [PubMed: 8376328]

37. Dieleman LA, Palmen MJHJ, Akol H, et al. Chronic experimental colitis induced by dextran sulphate sodium (DSS) is characterized by Th1 and Th2 cytokines. Clinical and Experimental Immunology. 1998; 114:385-91. [PubMed: 9844047]

38. Eswar N, Webb B, Marti-Renom MA, et al. Comparative protein structure modeling using MODELLER. Curr Protoc Protein Sci. 2007 Chapter 2:Unit 29.

39. Whitney JC, Colvin KM, Marmont LS, et al. Structure of the cytoplasmic region of PelD, a degenerate diguanylate cyclase receptor that regulates exopolysaccharide production in Pseudomonas aeruginosa. J Biol Chem. 2012; 287:23582-93. [PubMed: 22605337]

40. Eckburg PB, Bik EM, Bernstein CN, et al. Diversity of the human intestinal microbial flora. Science. 2005; 308:1635-8. [PubMed: 15831718]

41. Manichanh C, Rigottier-Gois L, Bonnaud E, et al. Reduced diversity of faecal microbiota in Crohn's disease revealed by a metagenomic approach. Gut. 2006; 55:205-11. [PubMed: 16188921]

42. Rajca S, Grondin V, Louis E, et al. Alterations in the intestinal microbiome (dysbiosis) as a predictor of relapse after infliximab withdrawal in Crohn's disease. Inflamm Bowel Dis. 2014; 20:978-86. [PubMed: 24788220]

43. Ryan RP. Cyclic di-GMP signalling and the regulation of bacterial virulence. Microbiology. 2013; 159:1286-97. [PubMed: 23704785]

44. Sarrabayrouse G, Bossard C, Chauvin JM, et al. CD4CD8alphaalpha Lymphocytes, A Novel Human Regulatory T Cell Subset Induced by Colonic Bacteria and Deficient in Patients with Inflammatory Bowel Disease. PLoS Biol. 2014; 12:e1001833. [PubMed: 24714093]

45. Hill DA, Artis D. Intestinal bacteria and the regulation of immune cell homeostasis. Annu Rev Immunol. 2010; 28:623-67. [PubMed: 20192812]

46. Atarashi K, Tanoue T, Oshima K, et al. Treg induction by a rationally selected mixture of Clostridia strains from the human microbiota. Nature. 2013; 500:232-6. [PubMed: 23842501]

47. Mazmanian SK, Round JL, Kasper DL. A microbial symbiosis factor prevents intestinal inflammatory disease. Nature. 2008; 453:620-5. [PubMed: 18509436]

48. Round JL, Mazmanian SK. Inducible Foxp3+ regulatory T-cell development by a commensal bacterium of the intestinal microbiota. Proc Natl Acad Sci U S A. 2010; 107:12204-9. [PubMed: 20566854]

49. Geuking MB, Cahenzli J, Lawson MA, et al. Intestinal bacterial colonization induces mutualistic regulatory T cell responses. Immunity. 2011; 34:794-806. [PubMed: 21596591]

50. Kwon HK, Lee CG, So JS, et al. Generation of regulatory dendritic cells and CD4(+)Foxp3(+) T cells by probiotics administration suppresses immune disorders. P Natl Acad Sci USA. 2010; 107:2159-64. 


\section{Summary Box}

\section{What is already known about this subject?}

- $\quad$ Crohn's disease (CD) associated dysbiosis is characterized by low proportion of Faecalibacterium prausnitzii in fecal and mucosaassociated microbiome.

- $\quad$ Loss of $F$. prausnitzii is predictive of CD relapse after surgery or in patients treated with immunosupressants.

- $\quad$ F. prausnitzii exhibits anti-inflammatory effects in vitro and in vivo by secreted metabolites that block NF- $\mathrm{kB}$ activation.

\section{What are the new findings?}

- $\quad$ F. prausnitzii produces bioactive peptides derived from a single $15 \mathrm{kDa}$ protein (ZP05614546.1) of unknown function named Microbial Antiinflammatory Molecule (MAM).

- $\quad$ MAM expression in epithelial cells lines is able to block the NF- $\kappa B$ pathway.

- $\quad$ Lactococcus lactis harboring a MAM-cDNA encoding plasmid is able to alleviate DNBS-colitis in mice

\section{How might this impact on clinical practice in the foreseeable future?}

- $\quad$ Discovery of anti-inflammatory molecules from a commensal bacterium such as $F$. prausnitzii constitutes the first step towards new anti-inflammatory drugs in $\mathrm{CD}$.

- $\quad$ Knowing the predictive value of $F$. prausnitzii for CD relapse, MAM could represent a targeted biomarker for CD. 


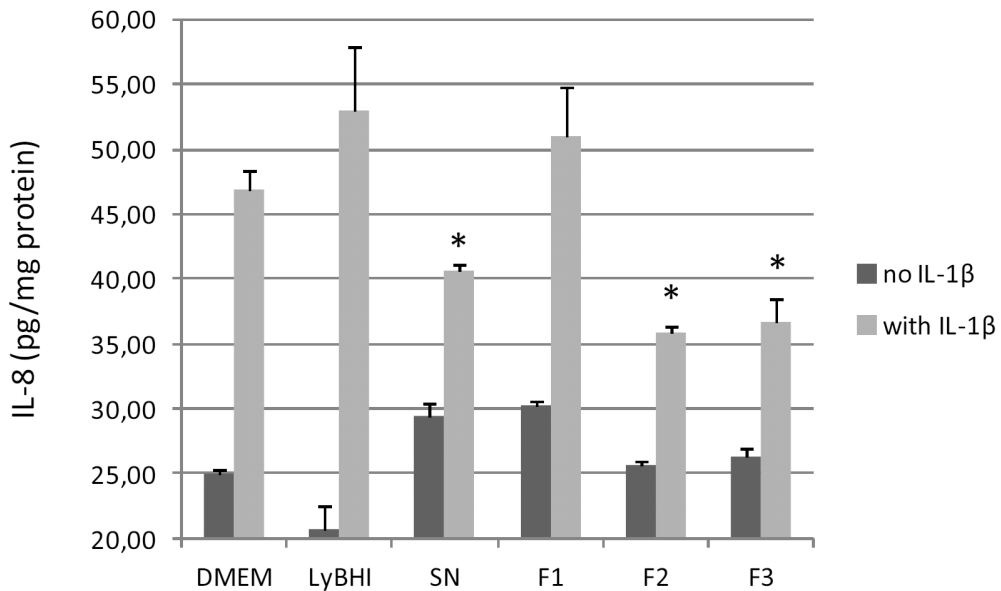

Figure 1.

IL-8 response of human Caco2 cells to stimulation in DMEM medium with IL-1 $\beta, F$. prausnitzii supernatant (SN) or LyBHI medium, and $F$. prausnitzii supernatant fractions $\mathrm{F} 1$ (20\% of acetonitrile), F2 (40\% acetonitrile) and F3 (80\% acetonitrile). The values are expressed as the mean \pm SEM in pg IL-8/mg protein. $* \mathrm{p}<0.05$ (compared to DMEM control with IL-1 $\beta$ in three experiments). 
A

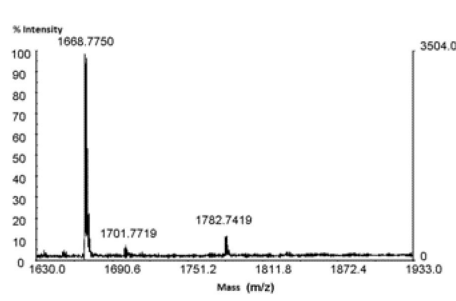

C
B

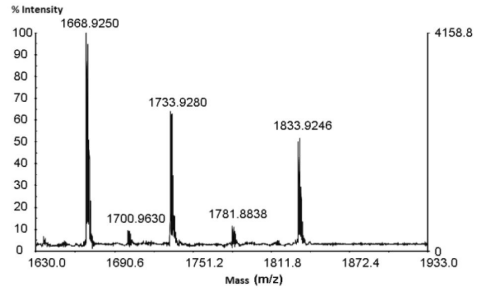

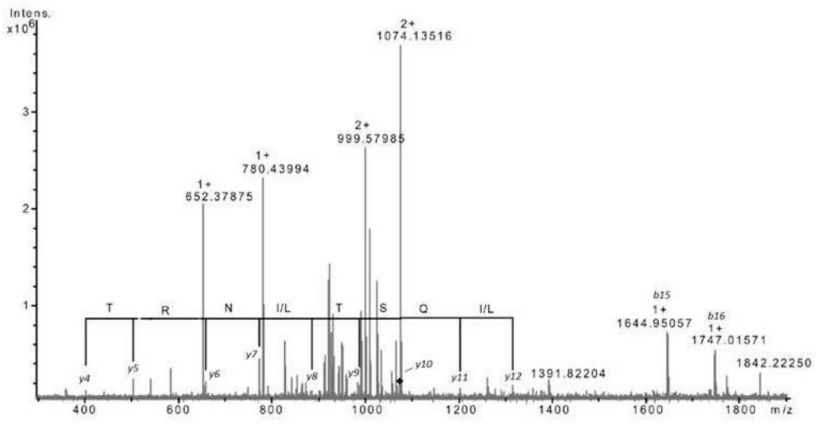

Figure 2.

(A) MALDI TOF MS spectra (zoom scan for the $m / z$ range 1630-1933) generated from F2' (A) and F2 fractions (B) showing two ions at $\mathrm{m} / \mathrm{z} 1733.93,1833.92$, only in (B) MS spectrum. (C) FTICR CID spectrum of the $[\mathrm{M}+2 \mathrm{H}]^{2+} \mathrm{m} / z 1073.61$ precursor ion (corresponding to the ion of interest $[\mathrm{M}+\mathrm{H}]^{+} \mathrm{m} / z$ 2146.94). De novo sequencing generated a probable partial amino acid sequence from singly charged ions. The accuracy of mass determination made it possible to attribute this series unambiguously and to differentiate between the isobaric amino acids $\mathrm{K}$ and $\mathrm{Q}$. 


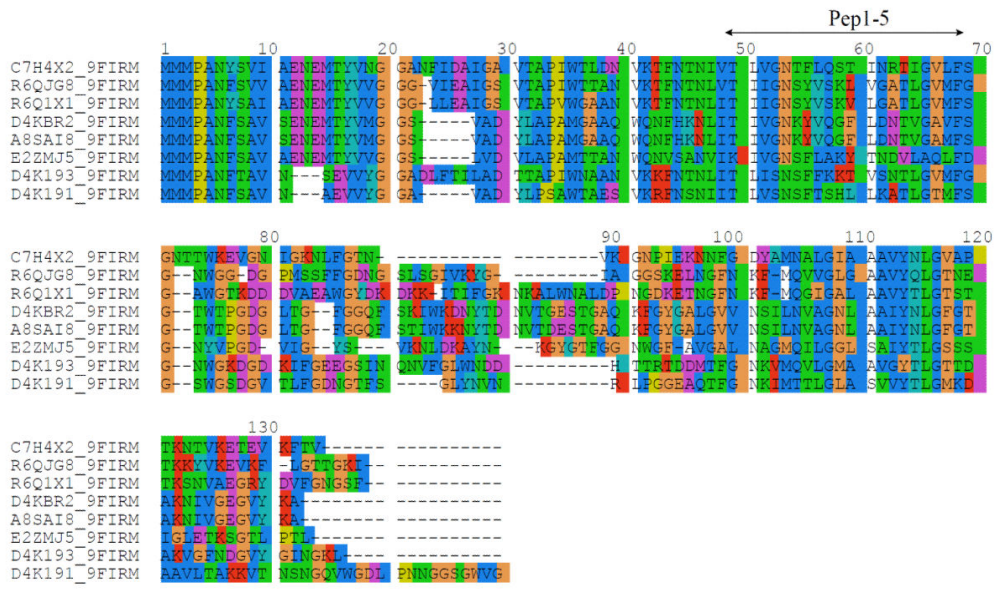

Figure 3.

Sequence alignments between MAM protein and 7 other homologous proteins of $F$. prausnitzii. Sequences were identified using a BLAST search and aligned using ClustalW2 program. The protein identifiers correspond to the following $F$. prausnitzii strains: $\mathrm{C} 7 \mathrm{H} 4 \mathrm{X} 2$, A2-165; R6QJG8 and R6Q1X1, sp. CAG:82; D4KBR2, SL3/3; A8SAI8, M21/2; E2ZMJ5, KLE1255; D4K191 and D4K193, L2-6. The region corresponding to identified peptides Pep1-5 is shown by an arrow. 

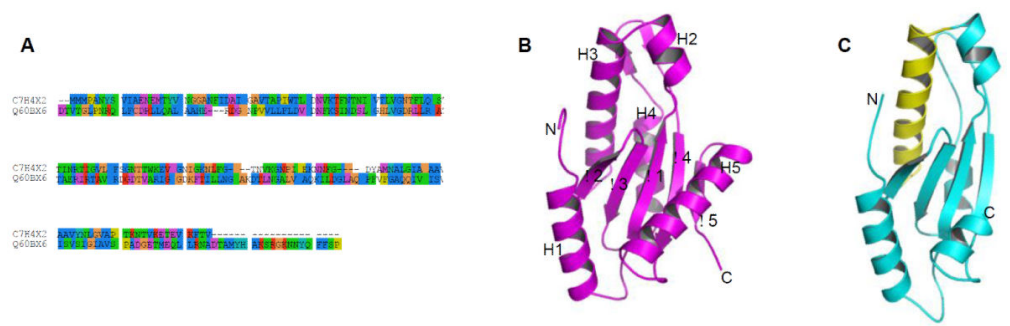

Figure 4.

Homology model of MAM protein based on a GGDEF domain template. (A) Sequence alignment of MAM and GGDEF protein from $M$. capsulatus (Q60BX6); (B) X-ray structure of template protein (PDB entry 3ICL) showing the secondary structure elements; (C) threedimensional model of MAM calculated with Modeller. The rms deviation on Ca positions of aligned residues is $1.1 \AA$. The region $49-68$ corresponding to the identified peptides Pep1-5 is coloured in yellow. 

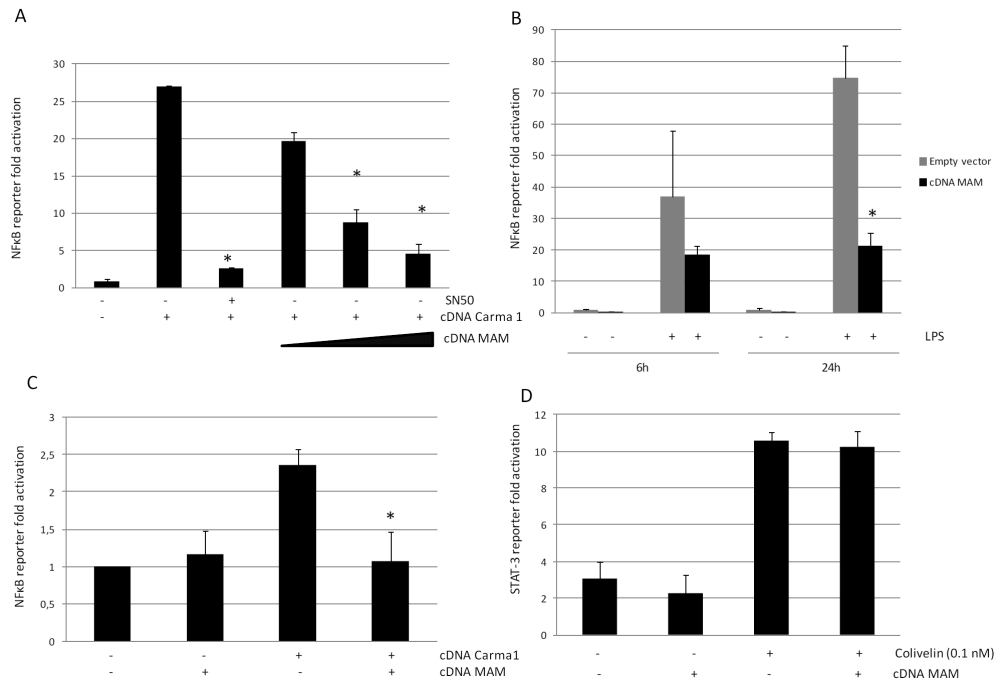

Figure 5.

Decrease in activation of the NF- $\kappa$ B pathway after transfection of MAM protein in different epithelial cells: in HEK293T in a dose-dependent manner (A), in TLR4/MD2/CD14 stably transfected HEK293T stimulated by LPS $100 \mathrm{ng}$. $\mathrm{mL}^{-1}$ (B) and in intestinal cells HT29 (C). SN50 $(50 \mu \mathrm{M})$ was used as positive control of NF- $\kappa$ B pathway inhibition in HEK293T. No activity of transfected MAM protein was observed on the STAT3 pathway activated by colivelin $0.1 \mathrm{nM}(\mathrm{D}) . * \mathrm{p}<0.05$ (compared to activation control). 


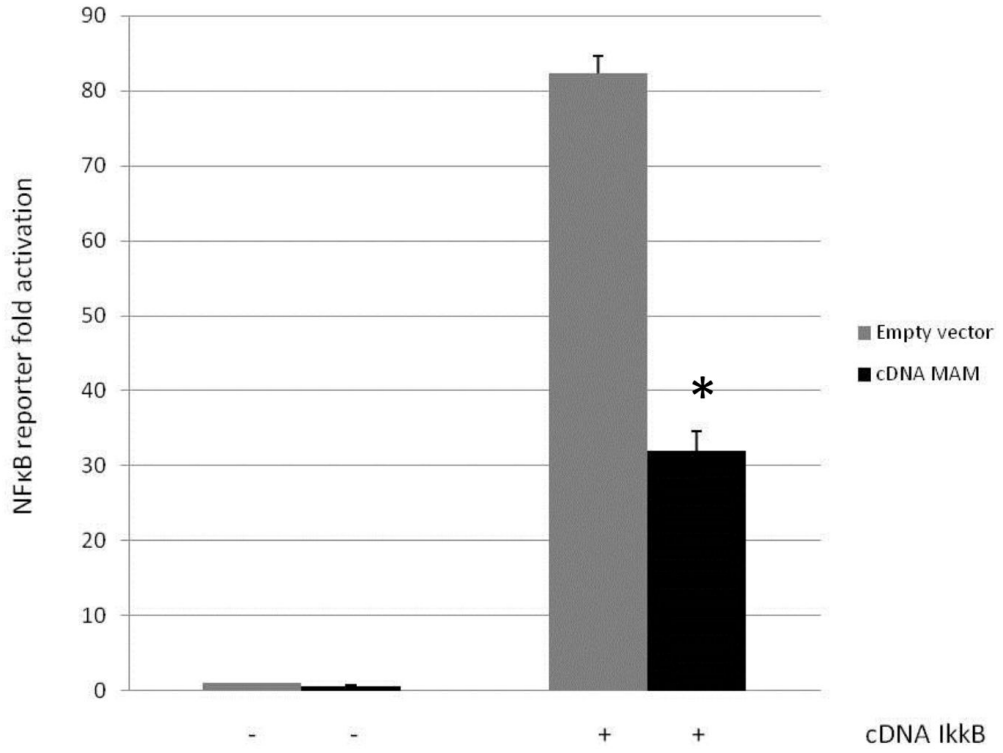

Figure 6.

Decrease in activation of the NF- $\kappa \mathrm{B}$ pathway after co-transfection of MAM protein and I $\kappa \kappa \mathrm{B}$ in HEK293T $(* \mathrm{p}<0.05)$ 


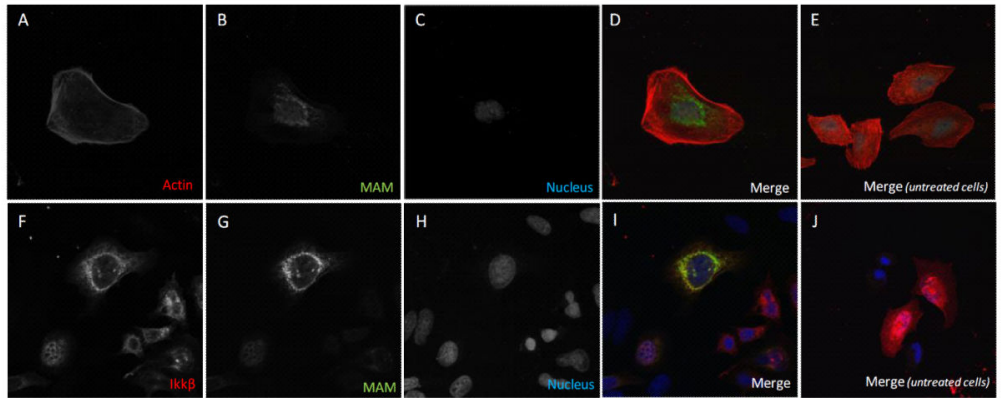

Figure 7.

Subcellular location of MAM protein in HeLa cells (A, B, C, D) and co-localisation of MAM protein with I $\kappa \kappa \beta$ in HEK293T cells (F, G, H, I). E and J labels correspond to staining controls in untreated cells. 


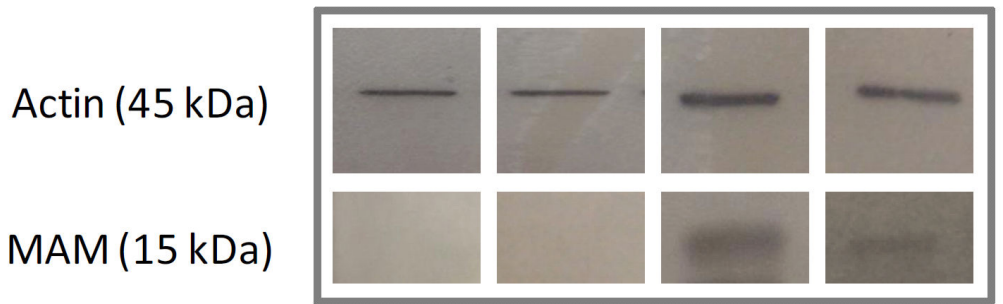

(1)

(2)

(3)

(4)

Figure 8.

Western blot with anti-flag antibody for MAM protein detection in small intestine enterocytes (1) and large intestine enterocytes (2) of mice fed with pILEmpty L. lactis and in small intestine enterocytes (3) and large intestine enterocytes (4) of mice fed with pILMAM L. lactis 

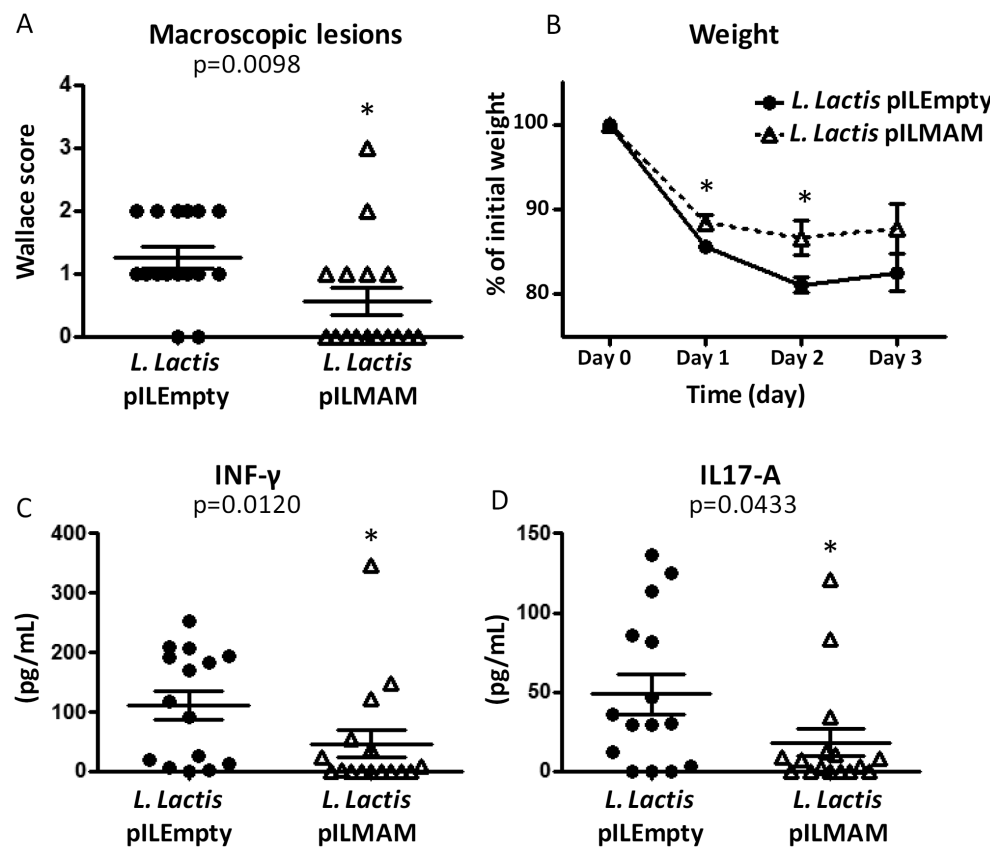

Figure 9.

Effects of intragastric administration of L. lactis bacterial suspension (pILMAM or Empty equivalent) on TNBS-induced colitis in C57BL/6 mice considering Wallace score (A), weight after induction of colitis (B) and quantification using ELISA of IL-17A (C) and INF$\gamma$ (D) in colons obtained $48 \mathrm{~h}$ after DNBS colitis induction (in $\mathrm{pg} / \mathrm{mL}$ of total proteins). The values are expressed as the mean \pm SEM $(* \mathrm{p}<0.05$ compared to L. lactis pILEmpty controls). 


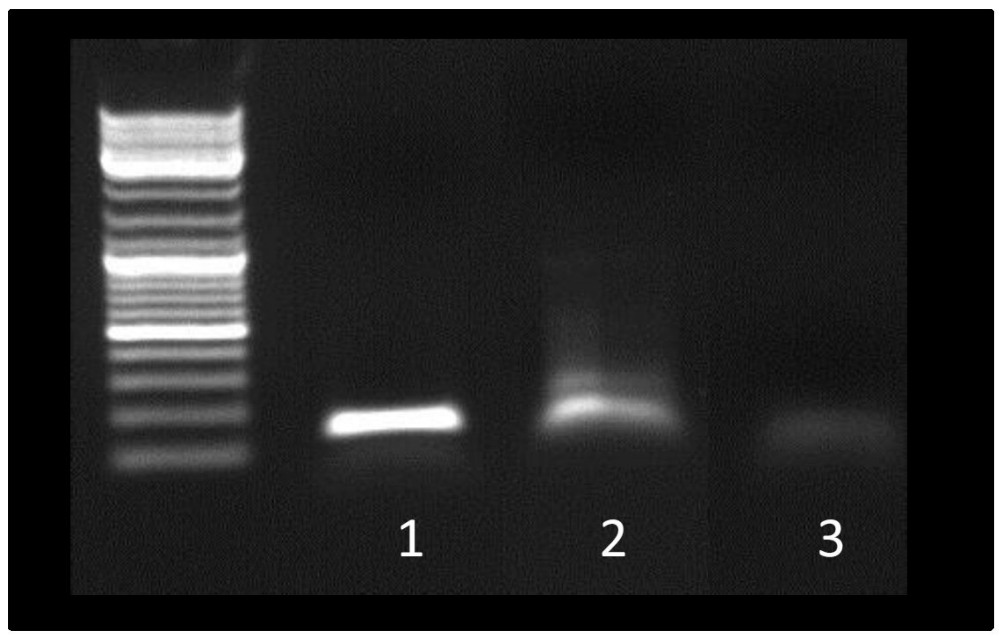

Figure 10.

PCR detection of MAM gene on RNA extract from feces of dixenic mice colonized with Faecalibacterium prausnitzii and Escherichia coli (1), on pILMAM plasmid (2, positive control) and on RNA extract of same sample (1) traited by RNAse before RT-PCR (3, negative control). 
Table 1

Sequences of the 7 peptides identified in F. prausnitzii supernatant and sequence of the MAM protein.

\begin{tabular}{|c|c|c|}
\hline Pep1 & 1732.95 Da & GNTFLQSTINRTIGVL \\
\hline Pep2 & 1832.02 Da & VGNTFLQSTINRTIGVL \\
\hline Pep3 & 1945.10 Da & LVGNTFLQSTINRTIGVL \\
\hline Pep4 & 2046.15 Da & TLVGNTFLQSTINRTIGVL \\
\hline Pep5 & 2145.26 Da & VTLVGNTFLQSTINRTIGVL \\
\hline Pep6 & $4600.28 \mathrm{Da}$ & FSGNTTWKEVGNIGKNLFGTNVKGNPIEKNNFGDYAMNALGIA \\
\hline Pep7 & 2578.40 Da & AAVYNLGVA PTKNTVKETE VKFTV \\
\hline \multicolumn{2}{|c|}{$\begin{array}{c}\text { Protein } \\
Z P 05614546.1\end{array}$} & $\begin{array}{l}\text { MMMPANYSVIAENEMTYVNGGANFIDAIGAVTAPIWTLDNVKTFNTNIVTLVGNTFLQSTINRTIG } \\
\text { VLFSGNTTWKEVGNIGKNLFGTNVKGNPIEKNNFGDYAMNALGIAAAVYNLGVA } \\
\text { PTKNTVKETEVKFTV }\end{array}$ \\
\hline
\end{tabular}

